\title{
Workplace Violence against Nursing Staff in Maternal and Child Health Centers at Qaliubiya Governorate
}

\section{Gehad Aboshady Mohammed, Hanaa Abd-El-Gawad Abd-El-Megeed ${ }^{2}$ and Wafaa Ata Mohammed ${ }^{3}$}

(1)B.Sc. Nursing, (2) Professor of Community Health Nursing, Faculty of Nursing, Benha University and (3) Lecturer of Community Health Nursing, Faculty of Nursing, Benha University

\begin{abstract}
Background: Workplace violence is a serious common, global and social problem in the medical settings. Nurses are primary victim of workplace violence due to close contact with patients and their relatives. Thus nurses are at greatest risk of being abused in $\mathrm{MCH}$ centers environment. Aim of the study: Was to assess workplace violence against nursing staff in maternal and child health centers. Research design: Descriptive research design was used to conduct this study. Setting: This study was conducted in $25 \%$ of the total number of for MCHCs in Qaliubiya Governorate (12 centers). Sample: All nurses in the selected centers (150 nurses) were included in the study. Tools of data collection: Two tools were used. I): Structured questionnaire divided in to five parts. 1) Assessment personal characteristics of the nurses. 2) Assessment exposure to violence in the work place in MCHs. 3) A- Assessment work characteristics and risk factors contributing to work place violence B- Assessment policies and regulations to deal with work place violence in MCHs. 4) Assessment nurse's knowledge regarding type of work place violence. 5) Assessment nurses' practice regarding prevention and management of workplace violence. II): Likert scale was used to measure attitude of MCHC nurses toward workplace violence. Results: $33.3 \%, 60.7 \%$ and $4.7 \%$ of nurses was exposed to physical, psychological and sexual violence at work. $14 \%$ of them had good knowledge regarding workplace violence, and 55\% of the nurses had negative attitude regarding workplace violence. Conclusion: More than half of nurses had average knowledge regarding work place violence. Less than two thirds of nurses had unsatisfactory practice toward prevention and management of workplace violence. Less than half of the studied nurses had positive attitude regarding workplace violence. Recommendations: Health education and training programs should be developed and implemented to upgrade the nurses' knowledge and practice toward prevention and management of workplace violence.
\end{abstract}

Key words: Workplace violence, MCHC, nurses.

\section{Introduction}

Violence is physical force used to injure, damage, or destroy. Violence is using of force to obtain from others what they are not willing to give or what they do not want to do resulting in injury, death, or psychological harm and has negative behavioral, emotional, cognitive and physical outcomes. Violence is a serious common, global and social problem in the medical setting. Nurses are primary victims of violence in medical settings (Mikolaj, 2020). 
Workplace physical violence against health care professionals perpetrated by patients and visitors has been a persistent problem worldwide. Workplace violence may result in reduction in job satisfaction, quality of life, productivity, increase in nurses' turnover that consequently might lead to increased medical errors, reduced quality of patient care, and adverse effects on nurse-patient communication (Ahmed, 2020).

Maternal and Child Health (MCH) refers to the promotive, preventive, curative and rehabilitative health care for mothers and children. It includes the sub areas of maternal health, child health, family planning, school health, handicapped children, adolescence, and health aspects of care of children in special settings such as day care (Li et al., 2020).

Community health nurses are equipped with skills and abilities that can make them integral in identifying workplace violence hazards, participating in workplace education, generating policy revision, supporting reporting protocol, and providing post-event emotional support, all essential aspects of a comprehensive workplace violence prevention program (Ferri et al., 2020).

\section{Significance of the study}

Work Place Violence (WPV) against nurses is a significant problem in health care setting in all over the world. In Egypt About $86 \%$ of the nurses working in obstetrics and gynecology departments in Cairo exposed to workplace violence. Around $66 \%$ of nurses working in $\mathrm{MCH}$ centers exposed to violence in Ismailia. The most common type of violence was the psychological type in the form of verbal abuse and disrespect by ignoring the nurse's presence, followed by physical violence and sexual harassment. In the main university hospital in Alexandria, the prevalence of violence exposure among nurses was $73 \%$ with the verbal violence as the most common type followed by physical and sexual violence (Egyptian Institute for Studies, 2019).

\section{Aim of the study}

The study aimed to assess workplace violence against nursing staff in Maternal and Child Health Centers at Qaliubiya Governorate

\section{Research questions:}

1-What are nurses` knowledge regarding workplace violence in Maternal and Child Health Centers?

2-What are nurses` attitudes regarding workplace violence in Maternal and Child Health Centers?

3-What are nurses` practice regarding workplace violence in Maternal and Child Health Centers?

\section{Subjects and Method}

\section{Research design:}

A descriptive study design was utilized to conduct the study.

\section{Setting:}

The total numbers of maternal and child health centers in Qaliubiya Governorate are 47 centers. The study was conducted for nurses working in 12 maternal and child health centers. It represents $25 \%$ of total 
centers. These centers are selected by cluster random sampling; three centers from each health directorate; from north directorate "Toukh MCH center -Kafr-Shoker $\mathrm{MCH}$ center- Kafr Tasfa MCH center), from south directorate "Elhady MCH center - Elkhanka $\mathrm{MCH}$ center $(\mathrm{B})$. Banha $\mathrm{MCH}$ center (A), from east directorate Bahtem $\mathrm{MCH}$ center (B)-Mostorod MCH center- Elhadayek MCH center) From west directorate (Begam $\mathrm{MCH}$ center.Shobra El Balad MCH center. Balks $\mathrm{MCH}$ center).Each center consists of obstetrics clinic, family planning clinic, detection clinic, dental clinic, vaccination clinic, an emergency clinic, and filing room.

\section{Study sample:}

A convenience sample of 180 nurses from the selected $\mathrm{MCH}$ centers were approached. During the process of data collection, 12 of nurses refused to continue in the study and 18 of nurses $(10 \%)$ for the pilot study which were excluded from the study. So, the final sample size was 150 nurses.

\section{Tools of data collection:}

Two tools were used in this study to collect the data: Tool I: Structured questionnaire sheet for nurses. This tool was developed by the investigator and included the following parts:

First Part: Personal characteristics of nurses as regards: Age, sex and educational level Second Part: Asses various types of violence that the nursing staff was exposed to in the workplace. It includes questions related to three types of violence "physical violence, psychological violence (Verbal abused) and sexual harassment.
1- Physical violence: included 5 multiple choice questions

2- $\quad$ Psychological violence: included 3 multiple choice questions

3- Sexual harassment: was composed of 4 multiple choice questions

\section{Third Part:}

A- Assess work characteristics and risk factors contributing to workplace violence against nursing staff, it included 12 multiple choice questions

B- Assessment policies and regulations to deal with workplace violence in $\mathrm{MCH}$ centers. It included 10 questions; the first three questions are answered by yes or no, the fourth and fifth questions are multiple choice questions related to workplace polices The last five multiple choice statements were answered by yes or no, which assess the regulations which are used to deal with violence in the workplace.

\section{Fourth Part:}

Assessment of nurses' knowledge regarding types of work place violence in $\mathrm{MCH}$ centers included 10 statements (Definition of workplace violence, reasons of the workplace violence, types of the workplace violence, definition of physical violence and the effects resulting from the physical violence, definition of psychological violence and the effects resulting from the psychological violence, definition of sexual harassment and the effects resulting from the sexual harassment and prevention of workplace violence).

Knowledge scoring system: Measuring the score of nurses' total knowledge about WPV, it was calculated as follows: (2) score 
for complete and correct answer, while (1) score for incomplete and correct answer and (0) score for incorrect answer or don't know. These scores of statements were summed up and the total divided by the number of the statements giving mean score for the part. These scores were converted into percent score. Nurses total knowledge score was classified as the following

Total scores of knowledge $=20$ points.

Good when the total score was $75 \%$ to 100\% (>15points).

Average when the total score was $50 \%$ to less than75\% (10-15 points).

Poor when the total score was less than $50 \%$ ( $<10$ points).

\section{Fifth Part:}

Included questionnaire to assess nurses' reported practice regarding prevention and management of workplace violence concerning on reaction toward workplace violence included 9 statements (Don't take any action, ask violent person to stop violence, try defense myself physically, ask device, tell manager, ask to transfer to another place, ask help, wait for legal action, take vacation).

Practices scoring system: (reported practice) was calculated for each statement as following: Done was scored 1 point and not done was scored zero point. The score of each statement summed-up and the total divided by the number of the statements, giving main score for the part. These scores were converted in to a percent score. As well as nurses total reported practices score was classified as the following:
Total scores of practices $=9$ points .

Satisfactory: when the total score was $\geq 80 \%$ ( $\geq 7$ points).

Unsatisfactory: when the total score was $<80 \%$ ( $<7$ points $)$.

\section{Tool II:}

Included Likert scale adopted from Samir et al., (2012) and was modified by investigator. 3 level likert scale (Agree uncertain- disagree) was used to measure attitude of maternal and child health centers nurses toward workplace violence. It was composed of 11 statements.

(Believe workplace violence threatens dignity of nursing, think workplace violence has psycho social consequence threaten the nursing being, think workplace violence affect nursing behavior, think workplace violence reduces nurses efficiency, think workplace violence effect nurse's relationship with worker, think workplace violence increase continuous changes of nurse's staff, feel desire to be silent during violence, see violence routine in day, see workplace increase dropouts the job ,believe that psychological violence most harmful than physical violence and believe that psychological violence most harmful than sexual violence).

Attitude scoring system: was calculated for each statement as follows: agree was scored 2 points, uncertain was scored 1 point and disagree was scored 0 point. The scores of the statements summed up and the total divided by the number of statements, giving mean score. These scores were converted into percent score nurses total attitude score was classified as following: 
Total scores of attitude $=22$ points.

Positive attitude: When the total score was $\geq 80 \%$ ( $\geq 18$ points).

Negative attitudes: When the total score was $<80 \%$ ( $<18$ points).

\section{Ethical considerations:}

Formal consent was obtained from each nurse after explaining the aim and nature of the study. Each nurse had the right to withdraw at any time nurses' verbal agreement to participate was obtained. Confidentiality of nurses' information was assured to all nursing staff.

\section{Content validity and reliability:}

Tools of the study were checked and revised by panel of five experts from Community Health Nursing Department, Faculty of Nursing at Benha University who reviewed the instruments for clarity, relevance, comprehensiveness, understanding and applicability and the modifications were done accordingly based on their responses. Reliability was applied by the investigator for testing the internal constancy of the tool, by administration of the same tools to the same subjects. CronbachIs Alpha reliability for knowledge was 0.857 , attitude .71 and for practice 0.82 .

\section{Pilot study:}

A pilot study was carried out before starting data collection on $10 \%$ from nurses' sample, and they were excluded from the total number of study sample. The aim of pilot study was to test the applicability, practicability of the tools and time needed. According to the results of the data analysis, items correction, modification, omission and addition were done accordingly.

\section{Field work:}

conducted by the investigator using the study tools for nurses in selected MCHs through a period of 6 months from begin July 2020 to December 2020.Investigator visited MCHC two day per week (Saturday -Tuesday) from 10 am to $1 \mathrm{pm}$, range nurses per day was 3-4 per day. Rota of shifts not fixed so investigator could meet and collected data from all nurses working in all shifts (morning, evening and night shifts).

\section{Statistical analysis:}

Computerized data entry and statistical analysis were done using SPSS (Statistical Package for Social Science), version 20. Descriptive statistics were first applied (numbers, frequency, percentages, tables, figures, diagrams and standard deviation).

\section{The following tests were done:}

Pearson's rank coefficient of correlation is the test statistics that measure the statistical relationship, or association, between two continues variables. Chi squares test of significance was used in order to compare proportions between two qualitative parameters. Such as:

Probability (p-value):

P-value $>0.05$ not significant.

$\mathrm{P}$-value $<0.05$ significant.

$P$-value $<0.001$ highly significant.

\section{Results:}

Table (1): Clarifies that personal characteristics of the studied nurse.it was clear that $84 \%$ of the nurses were females, 
50.7 of them were 30 to less than 40 years old with mean age $35.42 \pm 11.04$, and $58.7 \%$ of them had a diploma nursing.

Table (2): Indicates that65\%, 66\%, $61.3 \%$ and $6.7 \%$ of studied nurses had correct incomplete answers regarding definition, causes, harmful resulted from physical violence and psychological violence respectively. $78.7 \%$ had correct answer regarding types; $28.7 \%$ of nurses had correct answer about definition of sexual violence and $24.7 \%$ had correct answer about definition of violence.

Table (3): Represent that $78.7 \%$, $78 \%$ of studied nurses didn't (take a vacation, ask to transfer to another place) respectively, while $88.7 \%$ of them ask violent person to stop violence.

Table (4): Demonstrates that $88 \%$, $72.7 \%$ and $84.7 \%$ of studied nurses disagrees that workplace violence threatens dignity of nursing, workplace violence has psycho social consequence threaten being nurse and psychological violence most harmful than physical violence respectively.

Figure (1): Demonstrates that $55.3 \%$ of nurses had average knowledge; $30.7 \%$ of them had poor knowledge and $14 \%$ had good knowledge regarding violence.

Figure (3): illustrates that $62 \%$ of nurses had unsatisfactory level regarding reported practice toward prevention and management of workplace violence and $38 \%$ had satisfactory level.

Figure (3): Reveals that $55 \%$ of the studied nurses had negative attitude regarding workplace violence and only $45 \%$ of them had positive attitude.

Table (1): Frequency distribution of studied nurses regarding personal characteristics among studied nurses $(n=150)$.

\begin{tabular}{||l||c|c|}
\hline \multicolumn{1}{||c||}{ Personal characteristics } & No & \% \\
\hline Sex & 24 & 16.0 \\
\hline Male & 126 & 84 \\
\hline Female & 33 & 22.0 \\
\hline Age & 76 & 50.7 \\
\hline $20-$ & 41 & 27.3 \\
\hline $30-$ & \multicolumn{2}{|c|}{$35.42 \pm 11.04$} \\
\hline $40+$ & 88 & 58.7 \\
\hline Mean \pm SD & 35 & 23.3 \\
\hline Educational Level & 27 & 18.0 \\
\hline Diploma nursing & \multicolumn{2}{|c|}{} \\
\hline Technical institute of nursing &
\end{tabular}


Table (2): Frequency distribution of studied nurse regarding their knowledge about violence at maternal and child health centers among studied nurses $(\mathbf{n}=150)$.

\begin{tabular}{|c|c|c|c|c|c|c|}
\hline \multirow[t]{2}{*}{ Knowledge about workplace violence } & \multicolumn{2}{|c|}{$\begin{array}{c}\text { Correct } \\
\text { complete } \\
\text { answer } \\
\end{array}$} & \multicolumn{2}{|c|}{$\begin{array}{c}\text { Correct\& } \\
\text { Incomplete } \\
\text { answer }\end{array}$} & \multicolumn{2}{|c|}{$\begin{array}{c}\text { Incorrect } \\
\text { Incomplete } \\
\text { answer }\end{array}$} \\
\hline & No & $\%$ & No & $\%$ & No & $\%$ \\
\hline Definition & 37 & 24.7 & 84 & 56.0 & 29 & 19.3 \\
\hline Causes & 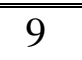 & 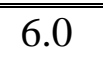 & 999 & 66.0 & 42 & 28.0 \\
\hline Types & 118 & 78.7 & 32 & 21.3 & 0 & 0 \\
\hline Definition of Physical violence & 36 & 24 & 85 & 56.7 & 29 & 19.3 \\
\hline Harmful result from physical violence & 26 & 17.3 & 92 & 61.3 & 32 & 21.3 \\
\hline Definition of Psychological violence & 22 & 14.7 & 80 & 53.3 & 48 & 32 \\
\hline Harmful result from Psychological violence & 23 & 15.3 & 103 & 68.7 & 24 & 16 \\
\hline Definition of Sexual violence & 43 & 28.7 & 64 & 42.7 & 43 & 28.7 \\
\hline Damage result from Sexual violence & 35 & 23.3 & 61 & 40.7 & 54 & 36 \\
\hline Prevention of workplace violence & 9 & 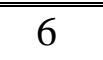 & 67 & 44.7 & 74 & 49.3 \\
\hline
\end{tabular}

Table (3): Frequency and percentage distribution of studied nurses regarding reported practices toward workplace violence at maternal and child health centers among studied nurses $(\mathbf{n}=150)$.

\begin{tabular}{|c|c|c|c|c|}
\hline \multirow{2}{*}{ Reported practices toward workplace violence } & \multicolumn{2}{|c|}{ Done } & \multicolumn{2}{|c|}{ Not done } \\
\hline & No & $\%$ & No & $\%$ \\
\hline \multicolumn{5}{|l|}{ Reaction toward workplace violence } \\
\hline Don't take any action & 39 & 26 & 111 & $\overline{74}$ \\
\hline Ask violent person to stop violence & 133 & 88.7 & 17 & 11.3 \\
\hline Try defense myself physically & 115 & 76.7 & 35 & 23.3 \\
\hline Ask device & 125 & 83.3 & 25 & 16.7 \\
\hline Tell my manager & 99 & 66 & $\overline{51}$ & 34 \\
\hline Ask to transfer to another place & 33 & 22 & 117 & 78 \\
\hline Ask help & 42 & 28 & 108 & $\overline{72}$ \\
\hline Waite for legal action & 100 & 66.7 & 50 & 33.3 \\
\hline Take vacation & 32 & 21.3 & 118 & 78.7 \\
\hline
\end{tabular}


Table (4): Frequency distribution of studied nurses regarding attitude toward workplace violence at maternal and child health centers among studied nurses $(n=150)$.

\begin{tabular}{|c|c|c|c|c|c|c|}
\hline \multirow{2}{*}{ Attitude toward workplace violence } & \multicolumn{2}{|c|}{ Agree } & \multicolumn{2}{|c|}{ Uncertain } & \multicolumn{2}{|c|}{ Disagree } \\
\hline & No & $\%$ & No & $\%$ & No & $\%$ \\
\hline Believe workplace violence threatens dignity of nursing & 9 & 3.73 & 9 & 3.73 & 132 & 88 \\
\hline $\begin{array}{l}\text { Think workplace violence has psycho social } \\
\text { consequence threaten the nursing being. }\end{array}$ & 8 & 5.3 & 33 & 22 & 109 & 72.7 \\
\hline Think workplace violence effect nursing behavior. & 9 & 3.73 & 45 & 30 & 96 & 64 \\
\hline Think workplace violence reduces nurses 'efficiency. & 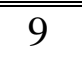 & 3.73 & 42 & 28 & 99 & 66 \\
\hline $\begin{array}{l}\text { Think workplace violence effect nurse's relationship } \\
\text { with worker. }\end{array}$ & 26 & 17.3 & 43 & 28.6 & 81 & 54 \\
\hline $\begin{array}{l}\text { Think workplace violence increase continuous changes } \\
\text { of nurse's staff. }\end{array}$ & 18 & 12 & 59 & 39.3 & 73 & 48.7 \\
\hline Feel desire to be silent during violence & 55 & 36.7 & 34 & 22.7 & 61 & 40.7 \\
\hline See violence routine in day & 33 & 22 & 31 & 20.7 & 86 & 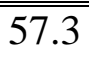 \\
\hline See workplace increase dropouts the job. & 7 & 4.7 & 44 & 29.3 & 99 & 66 \\
\hline $\begin{array}{l}\text { Believe psychological violence most harmful than } \\
\text { physical violence. }\end{array}$ & $\overline{77}$ & 4.7 & 16 & 10.7 & 127 & 84.7 \\
\hline $\begin{array}{l}\text { Believe psychological violence most harmful than } \\
\text { sexual violence. }\end{array}$ & 32 & 21.3 & 24 & 16 & 94 & 62.7 \\
\hline
\end{tabular}

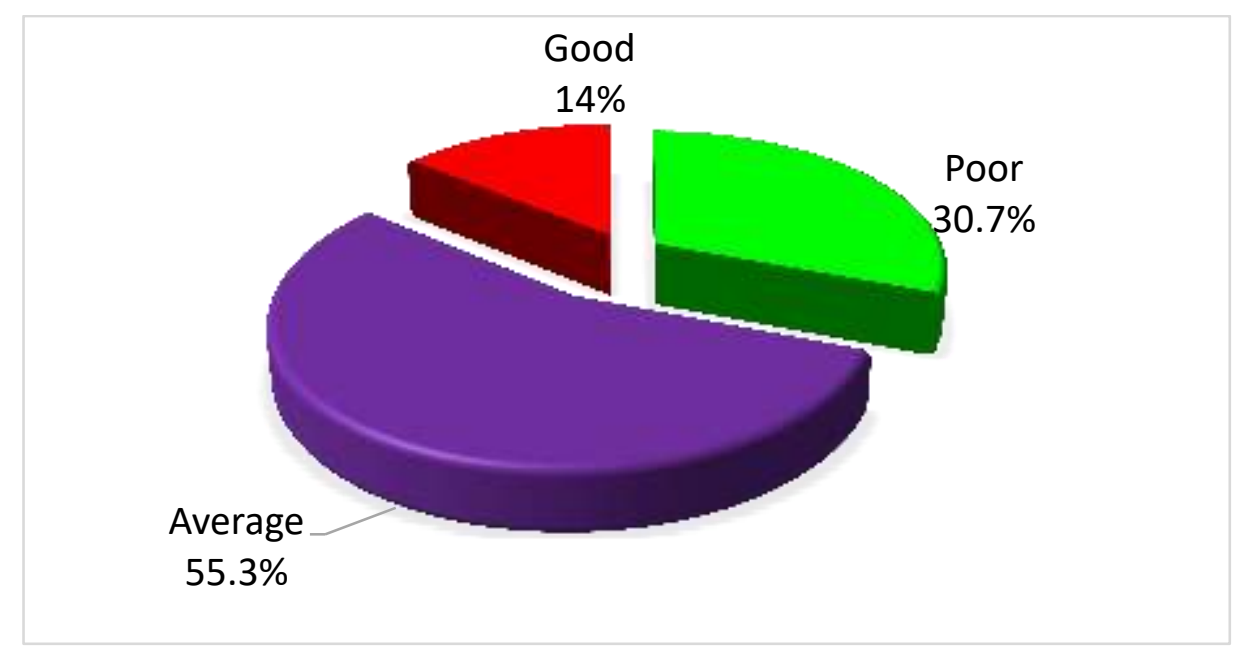

Figure (1): Percentage distribution of nurses' total knowledge regarding workplace violence 


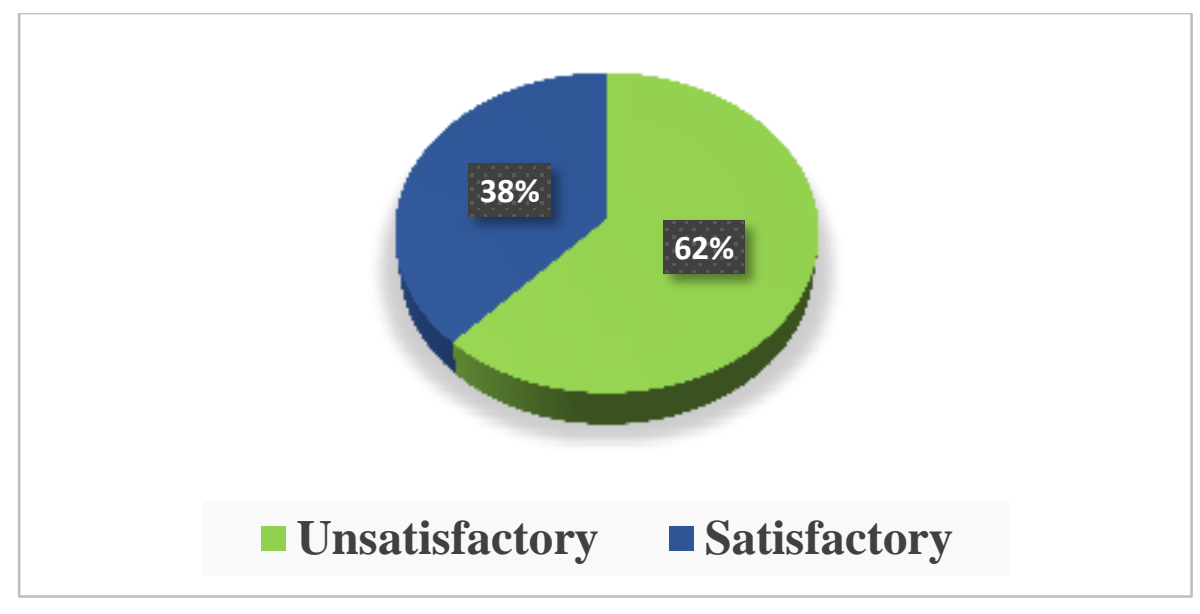

Figure (2): Percentage distribution of nurses' total reported practice toward workplace

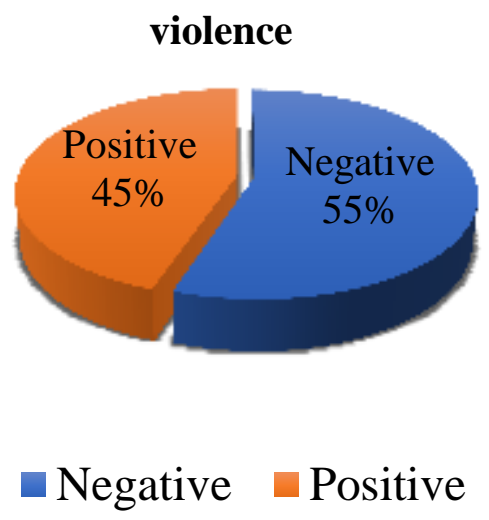

Figure (3): Percentage distribution of nurses' total attitude toward workplace violence.

\section{Discussion:}

Regarding to personal characteristics of studied nurse, the present study revealed that more than three quarters of the nurses were females and half of them aged from 30 to less than 40 years old with mean age $35.42 \pm 11.04$. Besides, more than half had a diploma nursing. These findings agreed with Boafo \& Hancock, (2017), who studied "workplace violence against nurses: a cross-sectional descriptive study of Ghanaian nurses, at Ghana", and showed that more than three quarters of the nurses were females and half of them aged from 30 to less than 40 years old with mean age $35.42 \pm$. This might due to all consider nursing profession is feminine.
Regarding to knowledge about workplace violence the present study revealed that more than three quarters of nurses had correct answer regarding types of workplace violence; more than one quarter had correct answer about definition of sexual violence and more than one third had correct answer about definition of violence. These findings agreed with Hassan et al., (2020) who studied workplace violence against nurses in Minia district hospitals in Egypt. They found that more than three quarters had correct answer regarding types of workplace violence; more than one quarter had correct answer about definition of sexual violence and more than one third had correct answer about definition of violence. According to these researchers, 
this may be due to lack of continuous education programed to nurses about work place violence.

Regarding total knowledge, current study showed that more than half of the nurses had average knowledge regarding workplace violence, less than one third) had poor knowledge and less than one fifth had good knowledge regarding violence. These findings contrast with Zahra\& Feng, (2020), who studied workplace violence against nurses in emergency departments in Indonesia. They showed that more than two thirds had good knowledge, more than one quarter had average knowledge and less than one fifth had good knowledge regarding violence. This might be due to high level of education; presence of training programs that increase awareness and knowledge regarding workplace violence. This might due to most of nurses' education of MCHC is diploma and defect in training programs to nurses.

Concerning on reported practices of studied nurses regarding workplace violence the current study described that more than four fifths of studied nurses asked violent person to stop while less than three quarters of them didn't asked to transfer to another place and took any vacation. These findings agreed with Jafree, (2017), who studied "workplace violence against female nurses working in two public sector hospitals of Lahore, Pakistan", and showed that that less than three quarters and more than four fifths took any action, ask violent person to stop respectively while less than three quarters did not do asked to transfer to another place. This might be due to nurses consider violence normal event in day and normal part of nursing job.
Regarding to total reported practice of studied nurses toward prevention and management of violence, the present study showed that less than two thirds had unsatisfactory level and more than one third had satisfactory level. This finding contrast with Lenaghan et al., (2018), who studied preventing emergency department violence through design. Journal of emergency nursing, Los Angeles showed that that more than three quarter had satisfactory level and less than one quarter had in unsatisfactory level. This might due to fear to take any action toward violence to avoid shame or stigma and mistrust.

Regarding attitude of studied nurses toward work place violence, current study demonstrated that more than four fiftieth disagree that workplace violence threatens dignity of nurses. More than two thirds disagree that workplace violence has psycho social consequences and threaten the wellbeing of nurses. More than three quarters of nurses disagree that psychological violence is more harmful than physical violence. This finding contrast with Najafi et al., (2017), who studied Human dignity and professional reputation under threat: Iranian Nurses' experiences of workplace violence in Iran. This study showed that psychological abuse appears to be more frequent and had negative effects and is more significant and more widespread. Work place violence threatens dignity of nursing. This might be due to nurses considering a patient always has right, lack of confidence in their professional abilities. They may also feel that they do not have the appropriate social position or level of prestige.

Considering total attitude of studied nurses regarding work place violence, the result of current study showed that more 
than half of the studied nurses had a negative attitude regarding violence and only less than half had a positive attitude. This finding contrast with Han et al., (2017), who studied workplace violence against emergency nurses in Taiwan, revealed that more than two thirds had a negative attitude regarding violence and only less than one third had a positive attitude. This might be due to lack of knowledge and experience on how to deal with violence.

\section{Conclusion:}

More than half of nurses had average knowledge regarding work place violence. Less than two thirds of nurses had unsatisfactory practice toward prevention and management of workplace violence. Less than half of the studied nurses had positive attitude regarding workplace violence.

\section{Recommendations:}

-Adequate safety measures, beneficial administrative procedures, and sincere efforts to overcome the causes of this phenomenon.

- Strict legislation to protect nurses and punish perpetrators could prevent future violence against nurses in MCHC.

- Training programs to help nurses to understand violence-related reasons and risk factors, warning signs, procedures for its avoidance, prevention and management, and reporting if it occurs should be established in the MCHC.

\section{References:}

Abdellah, F., \& Salama, M. (2017): Prevalence and risk factors of workplace violence against health care workers in emergency department in Ismailia,
Egypt. Pan African medical journal, 26(1): P 1-8.

Ahmed, R. (2020): Violence against women. International Egyptian Journal of Nursing Sciences and Research, 1(1):P1922.

Al Shdefat, A., \& Baker, R. (2020): Azero tolerance: A policy in workplace violence and aggression. TMR Integrative Nursing, 20(4): P 3.

Boafo, M. \& Hancock, P. (2017): Workplace Violence against Nurses: A cross Sectional Descriptive Study of Ghanaian Nurses, Sage Open, 7(1), ID, 2158244017701187.

Egyptian institute for studies, (2019): Addressing Risks: Mental Health, WorkRelated Stress, and Occupational Disease Management to Enhance Well-Being, monthly journal (4), ID 5430870

Ferri, P., Stifani, S., Accoto, A., Bonetti, L., Rubbi, I., \& Di Lorenzo, R. (2020): Violence against nurses in the triage area: a mixed-methods study. Journal of emergency nursing, 46(3): P 384-397.

Han, Y., Lin, C., Barnard, A., Hsiao, C., Goopy, S., \& Chen, C. (2017): Workplace violence against emergency nurses in Taiwan: A phenomenon graphic study. Nursing outlook, 65(4): P 428-435.

Hassan, E., Amein, M., \& Ahmed, M. (2020): Workplace violence against nurses at Minia district hospitals, Journal of Health Sciences, 10(1): P 76-82.

Jafree, R. (2017): Workplace violence against women nurses working in two public sector hospitals of Lahore, Pakistan. Nursing outlook, 65(4): P 420427. 
Kabbash, A., \& El-Sallamy, R. (2019): violence against health care workers in emergency hospital, Tanta University, EGYPT. Egyptian Journal of Occupational Medicine, 43(2): P 215-228.

Lenaghan, A., Cirrincione, M., \& Henrich, S. (2018): preventing emergency department violence through design, journal of emergency nursing Los Angeles, 44(1): P 7-12.

Li, Y., Li, R., QiU, D., \& Xiao, S. (2020): Prevalence of workplace physical violence against health care professionals by patients and visitors: a systematic review and metaanalysis, international journal of environment research and public health, 17 (1): P 299.

Mikołaj, K. (2020): Different forms of violence-selected issues. Review of european and comparative law, social european journal of social science and humanities, 43(4): P 103-118.

Najafi, F., Fallahi, M., Ahmadi, F., Dalvandi, A., \& Rahgozar, M. (2017): Human dignity and professional reputation under threat: Iranian Nurses' experiences of workplace violence. Nursing \& health sciences, 19(1): P 44-50.

Zahra, N., \& Feng, Y. (2018): Workplace violence against nurses in Indonesian emergency departments, Enfermeria clinica, 28 (2):P184-190. 
العنف بمكان العمل ضد هيئة التمريض بمر اكز رعاية الامومه والطفوله بمحافظة القليوبيه جهاد ابوشادي محم-هناء عبدالجواد عبدالمجيد- وفاء عطا محمج

يعد العنف في مكان العمل مشكلة عامة وعالمية واجتماعية خطيرة في الأوساط الطبية. المررضات هم

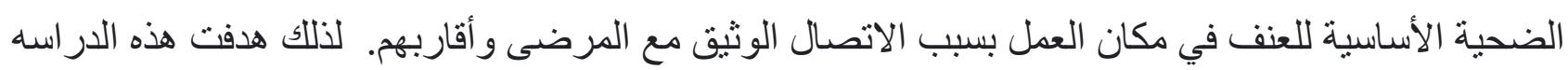

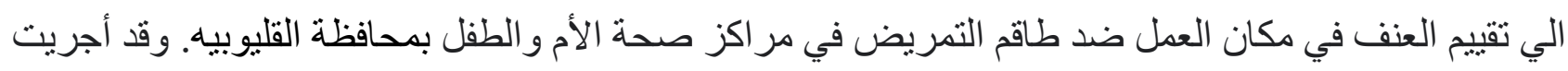

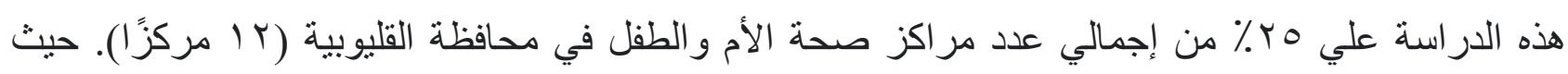

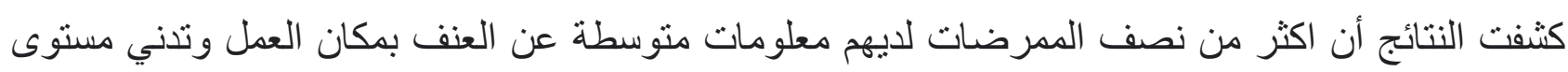

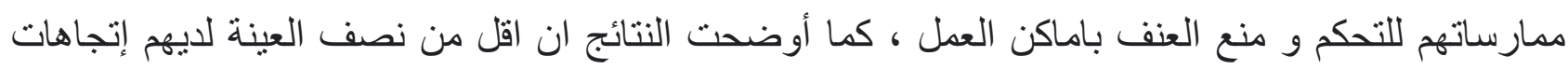

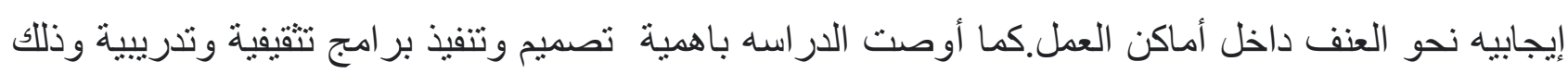

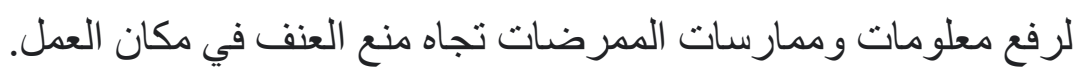

